\title{
BMJ Open Prevalence of tobacco use, exposure to secondhand smoke and knowledge on smoking cessation among students of health professions in Central Greece: a cross-sectional study
}

\author{
Athina A Samara (1) , ${ }^{1}$ George Rachiotis, ${ }^{2}$ Sofia Pettemeridou, ${ }^{3}$ \\ Konstantinos Papastamatiou, ${ }^{3}$ Konstantinos Tourlakopoulos, ${ }^{3}$ Eythimia Chelioti, ${ }^{3}$ \\ Antonis Katsioulis, ${ }^{2}$ Christos S Hadjichristodoulou (1) ${ }^{2}$
}

To cite: Samara AA, Rachiotis G, Pettemeridou S, et al. Prevalence of tobacco use, exposure to secondhand smoke and knowledge on smoking cessation among students of health professions in Central Greece: a crosssectional study. BMJ Open 2020;10:e036512. doi:10.1136/ bmjopen-2019-036512

- Prepublication history for this paper is available online To view these files, please visit the journal online (http://dx.doi. org/10.1136/bmjopen-2019036512).

Received 18 December 2019 Revised 30 August 2020 Accepted 04 September 2020

Check for updates

(c) Author(s) (or their employer(s)) 2020. Re-use permitted under CC BY-NC. No commercial re-use. See rights and permissions. Published by BMJ.

${ }^{1}$ Health and Hygiene, University of Thessaly Faculty of Medicine, Larissa, Greece

${ }^{2}$ Laboratory of Hygiene and Epidemiology, University of Thessaly Faculty of Medicine, Larissa, Greece

${ }^{3}$ Department of Hygiene and Epidemiology, University of Thessaly, Larissa, Greece

Correspondence to

Dr Athina A Samara;

at.samara93@gmail.com

\section{ABSTRACT}

Objectives The aim of this study was to assess the prevalence of tobacco use and exposure to secondhand smoke among students of health professions (SHPs) and determine possible risk factors for current smoking. In addition, we sought to investigate the level of students' knowledge regarding smoking cessation.

Design Cross-sectional.

Setting Central Greece.

Participants A convenient sample of 822 SHP volunteers were used, composed of 365 medical students, 123 students from a biochemistry department, 71 students from a nursing department, 176 from medical laboratory department and 84 students from a veterinary medicine department.

Primary and secondary outcome measures We investigated the prevalence of current smoking and secondhand smoke, their determinants and SHP's knowledge and attitudes regarding smoking cessation. Univariate and logistic regression statistical analysis were used in order to identify risk factors associated with current smoking. Results The prevalence of current smoking was estimated at $23.5 \%$ (95\% Cl $20.7 \%$ to $26.5 \%)$, while $49 \%$ of current smokers reported they wanted to quit smoking. The prevalence of current e-cigarette use was 1.2\%. In addition, 96.5\% (95\% Cl $94.9 \%$ to $97.5 \%$ ) of SHP have been exposed to secondhand smoke at least 1 day per week. Logistic regression analysis showed that increasing age $(p<0.001)$, alcohol consumption $(p<0.001)$ and exposure to secondhand smoke in the home $(p<0.001)$ were independent risk factors for current smoking. Notably, only $11.6 \%$ of the participants had learnt about methods to be used for smoking cessation.

Conclusions Our results underline the need for integrated tobacco control initiatives that should discourage tobacco use among SHP, promote smoke free schools of health science, and implement programs that train SHP in effective cessationcounseling techniques.

\section{INTRODUCTION}

Tobacco use is one of the major preventable causes of mortality and morbidity worldwide. WHO warns that tobacco use is one of
Strengths and limitations of this study

Our study provides for the first time, data on the determinants of smoking among students of veterinary medicine, biochemistry and medical laboratories departments.

- This was a questionnaire-based convenient sample study, and information bias may have occurred.

- Data were only collected from Central Greece; thus, the generalisability of our results is limited.

the primary risk factors for several chronic illnesses, including cancer, lung diseases and cardiovascular diseases. ${ }^{1}$ The tobacco epidemic is one of the greatest public health threats the world has ever faced, killing more than 7 million people each year. More than 6 million of those deaths are the result of direct tobacco use, while approximately 890 000 deaths are the result of non-smokers being exposed to secondhand smoke. ${ }^{1}$ Greece has one of the highest smoking rates of countries in the European Union. Each year, over 19000 Greeks die from tobaccoattributable illnesses such as cancers, cardiovascular and respiratory system diseases. ${ }^{2}$ Smoking-related conditions account for approximately $14.4 \%$ of the total healthcare costs in Greece, resulting in approximately $€ 3.4$ billion. $^{2}$ The 2013 Global Adult Tobacco Survey study measured the prevalence of current smoking in Greece at $38.2 \%(95 \%$ CI $35.7 \%$ to $40.8 \%) .{ }^{3}$ These findings are of concern and indicate the critical role of healthcare professionals, both as students in universities and during their later careers, to reduce the tobacco epidemic by counselling their patients on smoking cessation. 
Providing effective interventions against tobacco use, and counselling patients about smoking cessation is a core clinical skill that must be acquired during undergraduate health science studies. Counselling from students of health professions (SHPs) has shown increased smoking cessation rates. Data pooled from 17 trials of brief advice versus no advice detected a significant increase in the rates of cessation; however, there was only a small advantage provided by intensive advice versus minimal advice. ${ }^{4}$ Each contact with the patient, regardless of the reason for admission, could be an effective opportunity to support patients to quit smoking. ${ }^{5}$ According to Tobacco Use and Dependence Clinical Practice Guidelines developed by the US Public Health Service, all healthcare providers (HCPs) should promote tobacco cessation to all patients. ${ }^{6}$ Unfortunately, only half of all smokers receive advice on smoking cessation from any HCP, and even fewer receive pharmacotherapy. ${ }^{7-9}$

The tobacco epidemic seems to affect SHPs as well. The Global Health Professions Student Survey (GHPSS), which was conducted among third year medical students in 47 countries worldwide from 2005 to 2008, shows that over $20 \%$ of medical students are current smokers in 26 of 48 sites, and more than $40 \%$ in three countries (Bosnia and Herzegovina, Bolivia and Albania). ${ }^{10}$

Only a few studies have collected data on SHP's training on tobacco cessation methods, and even fewer studies exist regarding knowledge about this topic during the 6 years of medical school. The GHPSS mentioned above that was conducted among the third year medical students revealed that less than $40 \%$ of medical students reported receiving formal training on counselling patients to quit using tobacco. ${ }^{10}$ In 2011 in Greece, the rate of undergraduate SHPs who had received formal training on smoking cessation counselling was extremely low (ranging from $10.7 \%$ to $22.4 \%) .{ }^{11}$ In addition, the prevalence of current smoking among SHP is important according to the literature, since there is evidence that physicians who smoke are less likely to ask about patients' smoking history and provide advice for smoking cessation. ${ }^{12}$

Furthermore, to date, the GHPSS has only surveyed students belonging to departments of medicine, dentistry, nursing and pharmacy. However, other SHPs such as veterinarians, paramedics, biochemists and others may also play a role in tobacco use cessation. ${ }^{13}$

The main objectives of this study were to assess the prevalence of current smoking and secondhand smoke among various groups of SHPs in Central Greece; to identify independent risk factors of current smoking; and to compare knowledge on tobacco cessation methods among different schools of health professions.

\section{METHODS}

\section{Survey design-settings}

A cross-sectional questionnaire-based study was conducted. Participants received a structured, selfadministered modified version of the questionnaire used in the GHPSS Greece in 2011. ${ }^{11}$ The questionnaire was distributed during obligatory courses held in regular classroom settings. The study was conducted between March 2016 and June 2016.

\section{Data collection}

A convenient sample of SHPs at the University of Thessaly enrolled in the study. Medical students from all years of study, second and third year students from departments of biochemistry/medical laboratories/nursing, and third and fourth year students from the faculty of veterinary medicine participated in the survey. To make comparisons between preclinical and clinical study years, medical students from all years of study were selected to participate. Students from other schools of health professions who were in their middle years of study were selected to provide a more representative sample. The questionnaire consisted of 43 questions related to social characteristics, frequency of tobacco use, exposure to secondhand smoke, education and knowledge about risks of tobacco use and attitudes and methods for supporting patients to quit smoking.

As a first step, the GHPSS questionnaire was modified to include alcohol consumption information. The questionnaire was then translated from English to Greek, followed by back-translation into English to check for accuracy and compatibility with the core questionnaire. To address potential bias, the questionnaire was pilot tested in a sample of $20 \mathrm{SHP}$, who were asked to provide feedback on the face validity of the questionnaire. The questionnaire was then revised taking into consideration the pilot study results.

\section{Patient and public involvement}

Neither patients nor the public were directly involved with or participated in the research.

All participants were informed about the purpose of the study. On ensuring that participation was voluntary and that responses would remain anonymous and confidential, return of a completed questionnaire indicated informed consent.

\section{Primary outcome measures}

As current smoking was defined the use of tobacco products at least once on the past 30 days and as secondhand smoking was defined the exposure at home or public places at least once in the past 7 days.

\section{Statistical analysis}

Quantitative variables are presented as means with SD and qualitative variables are presented as absolute $(\mathrm{N})$ and relative $(\%)$ frequencies.

In univariable analysis, $\chi^{2}$ test tests or Fisher's exact tests were used to identify associations between categorical factors and smoking status. $\chi^{2}$ test for trend was used to explore any associations between ordinal factors and smoking status.

Logistic regression analysis was performed using the backward conditional method to identify independent 
factors for smoking status, adjusting for age and gender by calculating the ORs with the corresponding $95 \%$ CIs. Variables which were found to be statistically significant in univariable analysis were included in the logistic regression analysis. A result with a $\mathrm{p}<0.05$ was considered to be statistically significant. Data were analysed using Epi Info (V.3.5.3, CDC, Atlanta) and SPSS V.21.0 (IBM SPSS).

\section{RESULTS}

The response rates were $81 \%(365 / 450)$ among medical students, $61.5 \%(123 / 200)$ among students in the Biochemistry department, $56 \%$ (84/150) among students in the Veterinary Medicine department and $70.5 \%$ (247/350) among nursing/medical laboratories students.

The total sample consisted of 822 students, with a mean age of 21 years. Females represented $66.5 \%$ of the participants and males represented $33.5 \% ; 47.1 \%$ of participants were $<20$ years of age, $47.6 \%$ were $20-24$ years of age and $5.3 \%$ were older than 24 years of age. In total, $23.5 \%$ (95\% CI $20.7 \%$ to $26.5 \%$ ) of SHP were current smokers (females: $24.5 \%$, males: $21.5 \%$ ) with a mean number of 9.2 cigarettes smoked daily. Of the participants, $57.5 \%$ of SHP have used an e-cigarette before, but only 1.2\% are consistent users. Almost half of current SHP smokers (49\%) wanted to quit smoking in the past year, but only $20.7 \%$ of them received support from a health professional. In addition, $96.5 \%$ (95\% CI $94.9 \%$ to $97.5 \%$ ) of SHP have been exposed to secondhand smoke at least 1 day per week, and $41.4 \%$ of them in their own home. Furthermore, the vast majority of participants reported exposure to secondhand smoke in the school's restaurant—cafeteria (84.1\%) and in school buildings (77.4\%) (table 1).

In the univariate analysis of current smoking, association between increasing age and current smoking was identified. In fact, the prevalence of current smokers tended to increase with age $(\mathrm{p}=0.002)$. Medical students have the lowest rates of current smoking (17\%) while medical laboratories students have the highest rates $(32.4 \%)$; the smoking rate among students in the veterinary medicine department was $23.8 \%$ and $26.8 \%$ in the biochemistry department. The association between gender and current smoking was not statistically significant $(\mathrm{p}=0.332)$. In addition, the existence of an antismoking law banning smoking in school buildings and/ or clinics does not appear to affect the prevalence of smoking $(\mathrm{p}=0.985)$. Furthermore, knowledge regarding smoking related hazards does not reduce the prevalence of smoking ( $p=0.299)$. Tobacco use was significantly associated with alcohol consumption $(\mathrm{p}<0.001)$ and exposure to secondhand smoke at home $(\mathrm{p}<0.001)$ (table 2).

Logistic regression analysis showed that increasing age, alcohol consumption of $>70$ units per year, and exposure to secondhand smoke in the home were all independent risk factors for current smoking, while the school of study was not identified as an independent risk factor (table 3).
Table 1 Demographic and smoking-related characteristics

N $\%$

\begin{tabular}{lrr}
\hline Gender & & \\
Female & 547 & 66.5 \\
\hline Male & 275 & 33.5 \\
\hline Total & 822 & 100.0 \\
\hline Age group & & \\
$\quad \leq 20,0$ years old & 372 & 47.1 \\
20, 1-24, 0 years old & 376 & 47.6 \\
\hline >24, 0 years old & 42 & 5.3 \\
Total & 790 & 100.0 \\
\hline
\end{tabular}

Year of study

\begin{tabular}{lcc} 
First-second year & 409 & 49.9 \\
\hline Third-fourth year & 327 & 39.9 \\
\hline Fifth-sixth year & 84 & 10.2 \\
\hline Total & 820 & 100.0 \\
\hline School of health sciences training & \\
Biochemistry & 123 & 15.0 \\
\hline Medicine & 365 & 44.6 \\
\hline Veterinary medicine & 84 & 10.3 \\
\hline Nursing & 71 & 8.7 \\
\hline Medical laboratories & 176 & 21.5 \\
\hline Total & 819 & 100.0 \\
Have you ever smoked e-cigarette? & \\
\hline Yes & 509 & 61.9 \\
\hline No & 313 & 38.1 \\
\hline Total & 822 & 100.0 \\
Current smoking & & \\
Yes & 193 & 23.5 \\
\hline No & 629 & 76.5 \\
\hline Total & 822 & 100.0 \\
Secondhand smoking & & \\
\hline Yes & 792 & $96.5(94.9-97.5)$ \\
\hline Total & 821 & 100.0 \\
\hline
\end{tabular}

The vast majority of undergraduate SHP (91.9\%) believe that healthcare professionals should have adequate knowledge about smoking cessation, and 91.1\% believe that healthcare professionals should advise their patients to stop smoking. It is also worthy to mention that $81.3 \%$ of SHP recognise the special role that healthcare professionals play in advising their patients to quit smoking; $63.1 \%$ of SHP believe that if a healthcare professional advises a patient to stop smoking, the patient's odds of quitting increase. Only about one-fifth of participants $(21.5 \%)$ reported that healthcare professionals advise their patients to quit smoking. Additionally, more medical students believe that healthcare professionals are 'role models' for their patients and more broadly, society, in comparison to the rest of SHP $(\mathrm{p}<0.001)$ (table 4). 


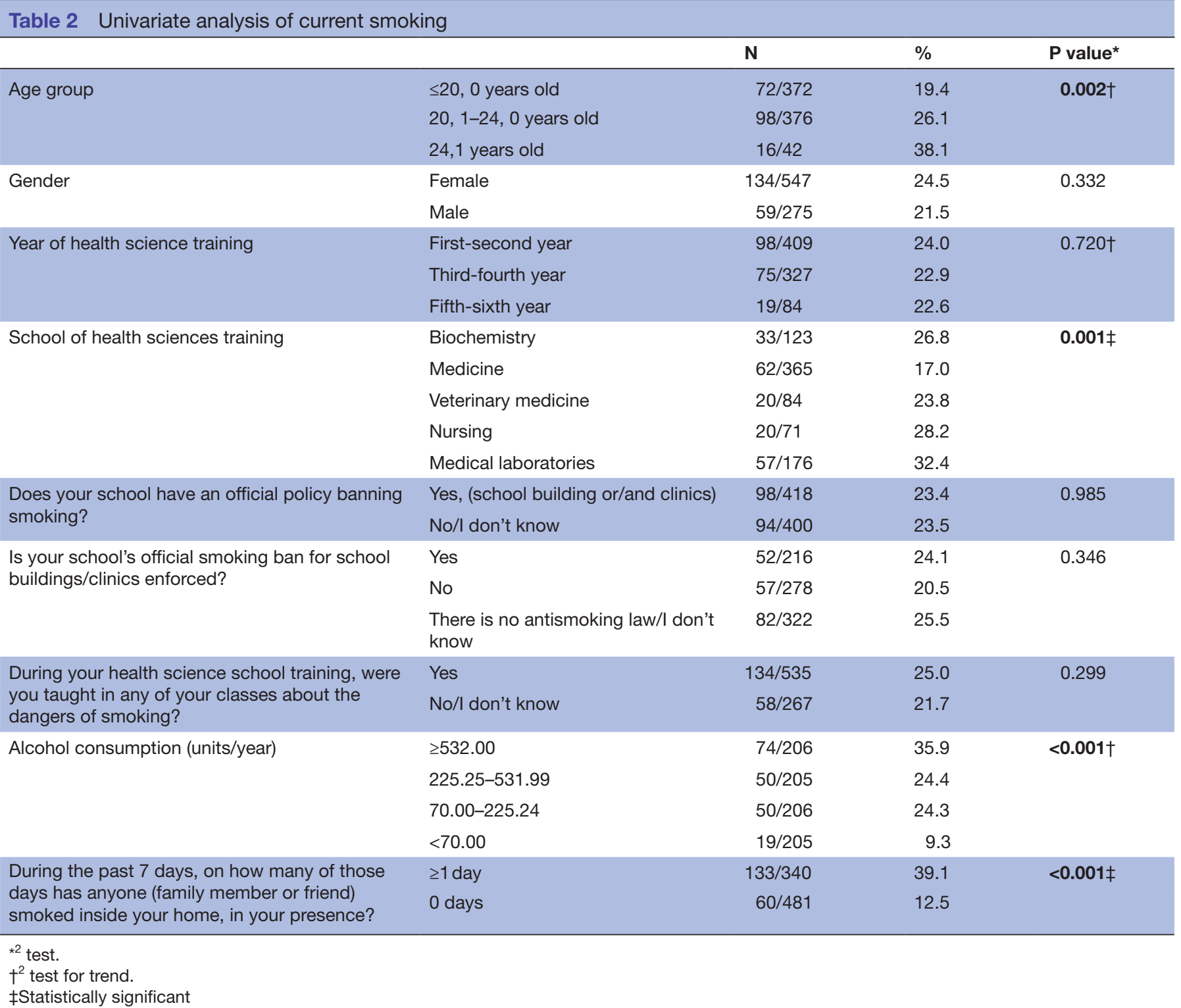

In total, $66.7 \%$ of undergraduate SHP reported that during their studies they learnt about smoking hazards, but only $36.8 \%$ have learnt about the reasons why people smoke. Furthermore, $56.1 \%$ of the respondents reported that they have learnt the importance of smoking history as a part of the patient's medical history. It is also worth noting that only $11.6 \%$ of respondents have learnt about using methods for smoking cessation, and only $27.1 \%$ have ever learnt the importance of providing informational materials against tobacco use to patients who want to quit smoking (table 5).

Medical students have a greater knowledge of the hazards associated with tobacco use $(p<0.001)$ as well as the reasons why people smoke $(\mathrm{p}=0.003)$, compared with undergraduate students of other health professions. Medical students have also shown a greater knowledge in recording a patient's smoking history as a part of the patient's medical history $(\mathrm{p}<0.001)$ and they better understand the importance of providing informational materials to patients who want to quit smoking $(\mathrm{p}<0.001)$.

\section{DISCUSSION}

In our study, the prevalence of current smoking among SHP was $23.5 \%$, while among medical students the prevalence was $17 \%$. As it concerns the prevalence of current smoking in European countries, the GHPSS reported this figure as $36.6 \%$ in Croatia, $21.7 \%$ in the Czech Republic, $34.7 \%$ in Serbia and $30.6 \%$ in Slovakia. ${ }^{10}$ Countrywide aggregate data from the GHPSS published in 2018 found the highest prevalence of current smoking in European countries (20\% medical and $40 \%$ dental students) and use of other tobacco products higher in eastern Mediterranean $(10 \%-23 \%)$ and European countries $(7 \%-13 \%){ }^{13}$ In 2011, the Greek GHPSS study found the prevalence of current smoking among SHP to be $28.8 \%$ among pharmacy students, $46.4 \%$ among health visitor students and 
Table 3 Logistic regression analysis of current smoking

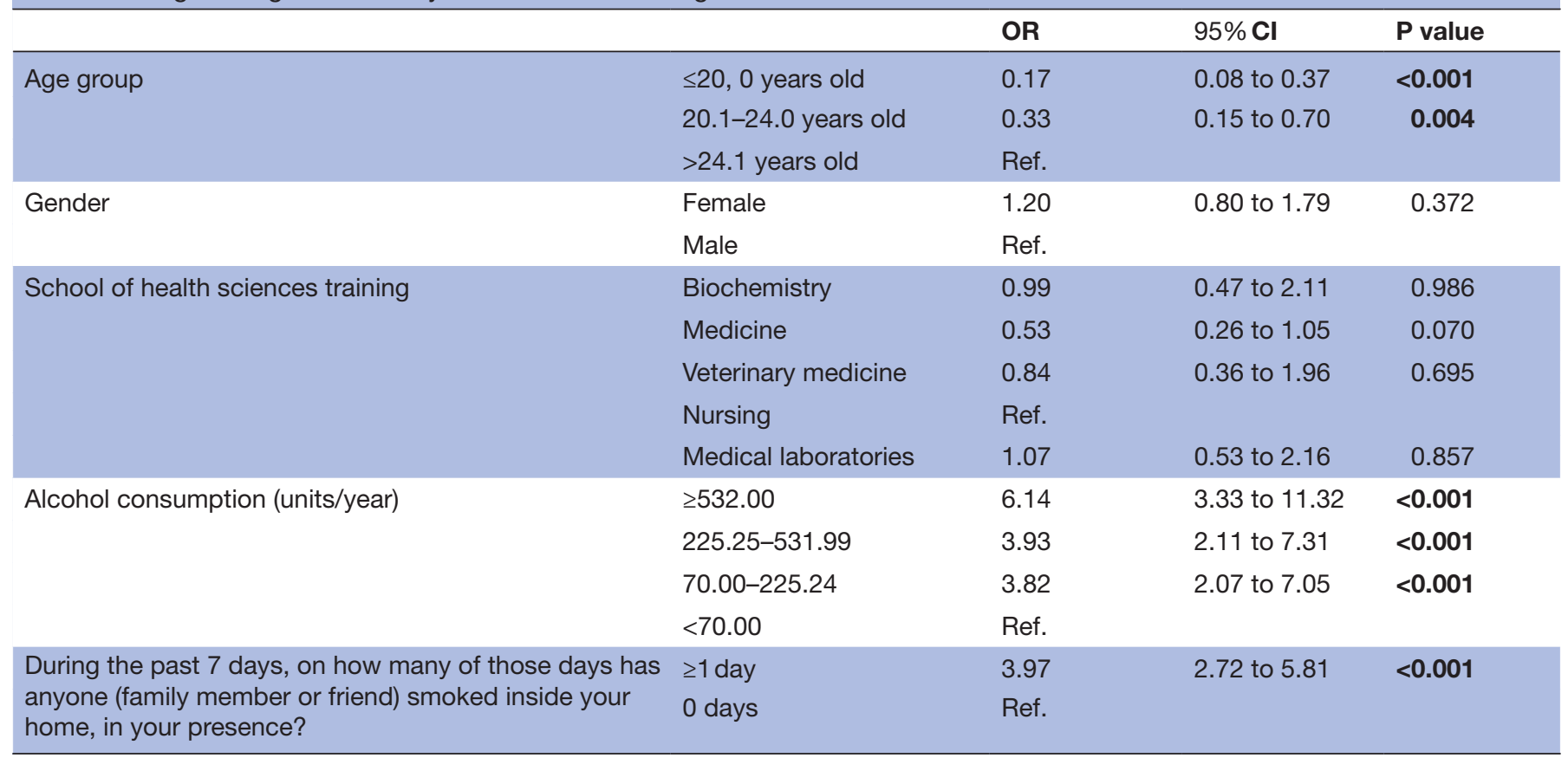

$29.5 \%$ among medical students. ${ }^{11}$ These figures reflect a possible reduction of current smoking prevalence among Greek SHP, in line with the decrease of smoking in the general population of Greece (measured at $38.2 \%$ in $2013 ; 42.6 \%$ in 2008). ${ }^{3}$

The extremely high rate of exposure to secondhand smoke at least 1 day per week $(96.5 \%$ in public places and $41.4 \%$ at home) corroborate previous studies from Greece, ${ }^{11} 14$ and indicate the urgent need for enforcement of tobacco banning policies in enclosed public places throughout the country. The existence of laws banning smoking in school buildings does not appear to affect the rates of smoking in these buildings, which is reflected through the high rates of exposure to secondhand smoke on the school campus $(84.1 \%$ in the school cafeteria and $77.4 \%$ in school buildings).
An interesting finding of our study was the extremely low rates, ranging between $4.7 \%$ for medical laboratory students and $14.4 \%$ for medical students, who have received training on smoking cessation counselling. In Greece in 2011, formal training on smoking cessation counselling among undergraduate SHP ranged from $10.7 \%$ to $22.4 \%$ (for health visitors and nursing students, respectively). ${ }^{11}$ In other countries belonging to the European Union (Germany, Italy, Poland and Spain), only $16.5 \%$ of students (lowest proportion in Italy at only $3.5 \%$ ) had reported training on smoking cessation during their studies in medical school. ${ }^{15}$ In the eastern Mediterranean region, a region close to Greece with social bonds and traditions similar to the Greek lifestyle, less than $30 \%$ of medical students had ever received formal training in smoking cessation methods. ${ }^{10}$ Regarding tobacco cessation methods, the vast majority of students had heard about

Table 4 Beliefs of students of health professions on their role in smoking cessation

\begin{tabular}{|c|c|c|c|}
\hline & \multicolumn{2}{|l|}{ Yes } & \multirow{2}{*}{$\begin{array}{l}\text { Total } \\
\mathbf{N} \\
\end{array}$} \\
\hline & $\mathbf{N}$ & $\%$ & \\
\hline Should healthcare professionals have special knowledge about smoking cessation? & 752 & 91.9 & 818 \\
\hline Healthcare professionals should advise their patients to stop smoking? & 746 & 91.1 & 819 \\
\hline If a healthcare professional advises a patient to stop smoking then the odds are increasing? & 517 & 63.1 & 819 \\
\hline $\begin{array}{l}\text { Do you believe that healthcare professionals advise their patients satisfactorily to stop } \\
\text { smoking? }\end{array}$ & 175 & 21.5 & 815 \\
\hline
\end{tabular}


Table 5 Curriculum and training about smoking and smoking cessation among students of health professions

\begin{tabular}{|c|c|c|c|c|c|c|c|c|c|c|c|c|}
\hline & & \multicolumn{2}{|c|}{ Biochemistry } & \multicolumn{2}{|c|}{ Medicine } & \multicolumn{2}{|c|}{$\begin{array}{l}\text { Veteriny } \\
\text { medicine }\end{array}$} & \multicolumn{2}{|c|}{$\begin{array}{l}\text { Medical } \\
\text { laboratories }\end{array}$} & \multicolumn{2}{|c|}{ Nursing } & \multirow[b]{2}{*}{ P value* } \\
\hline & & $\mathbf{N}$ & $\%$ & $\mathbf{N}$ & $\%$ & $\mathbf{N}$ & $\%$ & $\mathbf{N}$ & $\%$ & $\mathbf{N}$ & $\%$ & \\
\hline $\begin{array}{l}\text { During your studies, have you ever learnt } \\
\text { about smoking risks? }\end{array}$ & Total & 118 & 100 & 354 & 100 & 81 & 100 & 175 & 100 & 71 & 100 & $<0.001$ \\
\hline \multirow{2}{*}{$\begin{array}{l}\text { During your studies, have you ever } \\
\text { discussed the reasons why people start } \\
\text { smoking? }\end{array}$} & Yes & 45 & 38 & 139 & 39 & 27 & 32 & 48 & 27 & 35 & 49 & \multirow[t]{2}{*}{0.003} \\
\hline & Total & 119 & 100 & 353 & 100 & 84 & 100 & 175 & 100 & 71 & 100 & \\
\hline $\begin{array}{l}\text { During your studies, have you ever learnt } \\
\text { the importance of recording the smoking } \\
\text { history as a part of the medical history of } \\
\text { the patient? }\end{array}$ & Total & 118 & 100 & 353 & 100 & 84 & 100 & 175 & 100 & 71 & 100 & $<0.001$ \\
\hline \multirow{2}{*}{$\begin{array}{l}\text { During your studies, have you ever learnt } \\
\text { about using methods to stop smoking? }\end{array}$} & Yes & 12 & 10 & 51 & 14 & 10 & 12 & 8 & 4.7 & 10 & 14 & \multirow[t]{2}{*}{0.019} \\
\hline & Total & 118 & 100 & 353 & 100 & 84 & 100 & 172 & 100 & 70 & 100 & \\
\hline \multirow{2}{*}{$\begin{array}{l}\text { Have you ever heard about methods } \\
\text { for replacement of nicotine in smoking } \\
\text { cessation programmes (nicotine patch or } \\
\text { nicotine gum)? }\end{array}$} & Yes & 102 & 86 & 305 & 86 & 71 & 85 & 145 & 83 & 56 & 79 & \multirow[t]{2}{*}{0.527} \\
\hline & Total & 118 & 100 & 353 & 100 & 84 & 100 & 174 & 100 & 71 & 100 & \\
\hline \multirow{2}{*}{$\begin{array}{l}\text { Have you ever heard about using } \\
\text { antidepressant drugs in smoking cessation } \\
\text { programmes (like Bupropion, Zyban)? }\end{array}$} & Yes & 31 & 26 & 91 & 26 & 23 & 27 & 30 & 17 & 22 & 31 & \multirow[t]{2}{*}{0.107} \\
\hline & Total & 118 & 100 & 353 & 100 & 84 & 100 & 175 & 100 & 71 & 100 & \\
\hline
\end{tabular}

${ }^{*} \mathrm{X}^{2}$ test.

nicotine patches and gum, but only a quarter of them were aware of antidepressant medication use for this purpose. ${ }^{115}$

The majority of SHP $(59.9 \%)$ believe that their profession serves as a role model and they recognise the importance of learning smoking cessation techniques $(91.9 \%)$. These findings are in line with the GHPSS study conducted in Greece and internationally. ${ }^{10}{ }^{11}$ Medical students from Italy, Germany, the UK and the USA believe that health professionals should receive formal training in order to advise patients to quit smoking; however, these medical students have not received formal training during their studies, and as a result do not feel competent in providing counselling. ${ }^{16-19}$

WHO Framework Convention on Tobacco Control underlines the important role played by doctors, dentists, nurses, pharmacists and other health professionals in cessation and prevention of tobacco use through provision of brief counselling or even simple advice. ${ }^{20}$ However, health professionals who use tobacco themselves may be deterred from providing cessation advice and counselling to their patients. ${ }^{21}$ In this context, supporting SHP's efforts to stop smoking is essential. In Italy, smoking behaviour among SHP significantly changed after attending a university course for smoking cessation. ${ }^{22}$

In many medical schools worldwide, there is a limited or oftentimes even non-existent systemic approach to smoking cessation topics, although almost all medical schools include topics on tobacco related diseases. ${ }^{23} 24$ Evidence exists that medical students do not receive adequate medical education on tobacco use due to a variety of factors, such as impediments posed by staff, systemic and organisational challenges. ${ }^{25-27}$ Although considerable progress addressing tobacco teaching in medical schools has been made globally, more intensive efforts are needed in order to establish education on tobacco use as an ongoing part of medical curricula. ${ }^{28}$

As it was expected, there was a significant difference between medical students and non-medical students of other healthcare professions regarding their knowledge of smoking related diseases; however, medical students were not shown to have a statistically significant greater knowledge about smoking cessation techniques. Similar results have been reported in Italian medical students, who have marginally higher knowledge about smokingrelated diseases and cessation methods than non-medical students. ${ }^{29}$

Alcohol consumption of more than 70 units per year and exposure to secondhand smoke in the home were independent risk factors for current smoking. The relationship between smoking and alcohol consumption underlines the need for common targeting campaigns. Being exposed to smoking contributes to the development of a positive attitude towards tobacco use as a social norm, and increases the tendency to smoke. ${ }^{30}$ Alcohol consumption is negatively associated with successful smoking cessation in both community and clinical research. ${ }^{3132}$

Considering the fact that nurses comprise the majority of health professionals, efforts must be made to improve 
the quality of undergraduate education in Nursing school, with respect to tobacco control and smoking cessation methods. Other HCPs, like veterinarians, biochemists and medical laboratory's workers serve as role models in society. Several studies have reported the potential harms of tobacco exposure in dogs, cats and other pets' health. ${ }^{334}$ In this prospect, veterinarians could advice pet owners quit smoking in every visit in order to improve both pet's and owner's health. In everyday clinical practice, very brief advice is an evidence-based, effective and time-efficient way of improving quality of life for patients, saving money and increasing paramedic job satisfaction. ${ }^{35}$ More study is needed on paramedics potential role providing advice on smoking cessation.

Our survey presents both advantages and limitations. The main advantage of this study is the fact that it provides for the first time, data on the determinants of smoking among SHPs. In addition, for the first time data is presented on smoking-related variables from students of paramedical, biochemistry and veterinary health professions. The main limitation of our study is the selfreported nature of data selected, where students might under-report or over-report their behaviours or attitudes. The extent of misclassification bias cannot be determined from this data, since there is no biochemical verification of smoking status. In a cross-sectional study in Kyrgyzstan, when self-reported non-smokers having $\mathrm{CO} \geq 7 \mathrm{ppm}$ were included, the smoking prevalence increased from $35.0 \%$ to $44.8 \% .{ }^{36}$ Our sample was convenient and selection bias may have occurred; we were also not able to obtain data from the non-responders, and thus, there is a potential for selection bias. Lastly, our study was cross-sectional, and consequently, we cannot test cause and effect.

The findings of this study underline the need for the development of effective tobacco-related curricula, especially for medical and nursing students. This curricula will enable SHPs to assist smokers to quit, and to counsel nonsmokers (adolescents and adults) to prevent smoking initiation among them. This systemic approach can lead to a new generation of healthcare professionals who can contribute substantially to the control of the smoking epidemic in Greece. Integrated tobacco control initiatives should discourage tobacco use among SHPs, promote smoke-free schools of health professionals, and implement programmes that will train SHP in effective smoking cessation-counselling techniques.

\section{CONCLUSIONS}

The present study found a high prevalence of current smoking and secondhand smoke among SHPs in Central Greece. Considerable knowledge gaps among SHPs related to smoking cessation were identified. Campaigns targeting SHP, as well as curriculum alterations should be implemented. The association between alcohol consumption and current smoking deserves further investigation for the development of common prevention programmes.

Correction notice Collaborators section is corrected.
Collaborators Lemonia Anagnostopoulos.

Contributors AAS participated in study design, collecting questionnaires, drafting and revising the manuscript. GR participated in study design, drafting and revising the manuscript. SP, KP, KT and EC participated in study design and collecting the questionnaires. AK participated in statistical analysis. CSH supervised study design and the implementation of the study, participated in statistical analysis, interpretation of results and revision of the manuscript. All authors have read and approved the final version of the manuscript.

Funding The authors have not declared a specific grant for this research from any funding agency in the public, commercial or not-for-profit sectors.

Competing interests None declared.

Patient and public involvement Patients and/or the public were not involved in the design, or conduct, or reporting, or dissemination plans of this research.

Patient consent for publication Obtained.

Ethics approval The protocol of the study has been approved by the Research Ethic Committee of the University (N/A-02/2016).

Provenance and peer review Not commissioned; externally peer reviewed.

Data availability statement Data are available on reasonable request.

Open access This is an open access article distributed in accordance with the Creative Commons Attribution Non Commercial (CC BY-NC 4.0) license, which permits others to distribute, remix, adapt, build upon this work non-commercially, and license their derivative works on different terms, provided the original work is properly cited, appropriate credit is given, any changes made indicated, and the use is non-commercial. See: http://creativecommons.org/licenses/by-nc/4.0/.

ORCID iDs

Athina A Samara http://orcid.org/0000-0002-6177-7281

Christos S Hadjichristodoulou http://orcid.org/0000-0002-4769-8376

\section{REFERENCES}

1 WHO. Tobacco fact sheet (updated May 2017). Available: http:// www.who.int/mediacentre/factsheets/fs339/en/ [Accessed 12 Jan 2017].

2 Harvard School of Public Health. The Greek tobacco epidemic, 2011. Available: http://www.who.int/fctc/reporting/party_reports/greece annex1_the_greek_tobacco_epidemic_2011.pdf [Accessed 12 Jan 2017].

3 Rachiotis G, Barbouni A, Katsioulis A, et al. Prevalence and determinants of current and secondhand smoking in Greece: results from the global adult tobacco survey (GATS) study. BMJ Open 2017;7:e013150.

4 Stead LF, Buitrago D, Preciado N, et al. Physician advice for smoking cessation. Cochrane Database Syst Rev 2013:CD000165.

5 Çakir B, Tas A, Sanver TM, et al. Doctor's enquiry: an opportunity for promoting smoking cessation-findings from global adult tobacco surveys in Europe. Eur J Public Health 2017;27:921-5.

6 Fiore MC, Jaen CR, Baker TB, et al. Treating tobacco use and dependence: 2008 update. clinical practice guideline. Rockville, MD: US Department of Health and Human Services, Public Health Service, 2008. http://www.ncbi.nlm.nih.gov/books/NBK63954

7 Danesh D, Paskett ED, Ferketich AK. Disparities in receipt of advice to quit smoking from health care providers: 2010 National health interview survey. Prev Chronic Dis 2014;11:E131.

8 Ferketich AK, Gallus S, Colombo P, et al. Use of pharmacotherapy while attempting cessation among Italian smokers. Eur J Cancer Prev 2009;18:90-2.

9 Ferketich AK, Khan Y, Wewers ME. Are physicians asking about tobacco use and assisting with cessation? results from the 20012004 national ambulatory medical care survey (NAMCS). Prev Med 2006;43:472-6.

10 Warren CW, Sinha DN, Lee J, et al. Tobacco use, exposure to secondhand smoke, and cessation counseling among medical students: cross-country data from the global health professions student survey (GHPSS), 2005-2008. BMC Public Health 2011;11:72.

11 Barbouni A, Hadjichristodoulou C, Merakou K, et al. Tobacco use, exposure to secondhand smoke, and cessation counseling among health professions students: Greek data from the global health professions student survey (GHPSS). Int J Environ Res Public Health 2012;9:331-42.

12 Tong EK, Strouse R, Hall J, et al. National survey of U.S. health professionals' smoking prevalence, cessation practices, and beliefs. Nicotine Tob Res 2010;12:724-33. 
13 Sreeramareddy CT, Ramakrishnareddy N, Rahman M, et al. Prevalence of tobacco use and perceptions of student health professionals about cessation training: results from global health professions students survey. BMJ Open 2018;8:e017477.

14 Patelarou E, Vardavas CI, Ntzilepi P, et al. Nursing education and beliefs towards tobacco cessation and control: a cross- sectiona national survey (GHPSS) among nursing students in Greece. Tob Induc Dis 2011;9:4.

15 La Torre G, Kirch W, Bes-Rastrollo M, et al. Tobacco use among medical students in Europe: results of a multicentre study using the global health professions student survey. Public Health 2012;126:159-64.

16 Ferrante M, Saulle R, Ledda C, et al. Prevalence of smoking habits, attitudes, knowledge and beliefs among health professional school students: a cross-sectional study. Ann Ist Super Sanita 2013;49:143-9.

17 Grassi MC, Chiamulera C, Baraldo M, et al. Cigarette smoking knowledge and perceptions among students in four Italian medical schools. Nicotine Tob Res 2012;14:1065-72.

18 Raupach T, Shahab L, Baetzing S, et al. Medical students lack basic knowledge about smoking: findings from two European medical schools. Nicotine Tob Res 2009;11:92-8.

19 Springer CM, Tannert Niang KM, Matte TD, et al. Do medical students know enough about smoking to help their future patients? assessment of new York City fourth-year medical students' knowledge of tobacco cessation and treatment for nicotine addiction. Acad Med 2008;83:982-9.

20 WHO. WHO framework convention on tobacco control. Geneva: World Health Organization, 2014.

21 Smith DR, Leggat PA. An international review of tobacco smoking among medical students. J Postgrad Med 2007;53:55-62.

22 LA Torre G, D'Egidio V, Patrissi R, et al. Effectiveness of a training course on smoking cessation knowledge and behaviour for health profession students: the SISMA project. J Prev Med Hyg 2019;60:E119-23.

23 Chatkin J, Chatkin G. Learning about smoking during medical school: are we still missing opportunities? Int J Tuberc Lung Dis 2009;13:429-37.
24 Crofton JW, Tessier JF, Fréour PP, et al. European medical schools and tobacco. Med Educ 1996;30:424-7.

25 Richmond R. Teaching medical students about tobacco. Thorax 1999;54:70-8.

26 Richmond RL, Debono DS, Larcos D, et al. Worldwide survey of education on tobacco in medical schools. Tob Control 1998;7:247-52.

27 Richmond R, Taylor R. Global dissemination of a tobacco curriculum in medical schools. Int $J$ Tuberc Lung Dis 2006;10:750-5.

28 Richmond R, Zwar N, Taylor R, et al. Teaching about tobacco in medical schools: a worldwide study. Drug Alcohol Rev 2009;28:484-97.

29 Grassi MC, Baraldo M, Chiamulera C, et al. Knowledge about health effects of cigarette smoking and quitting among Italian university students: the importance of teaching nicotine dependence and treatment in the medical curriculum. Biomed Res Int 2014;2014:321657

30 Leonardi-Bee J, Jere ML, Britton J. Exposure to parental and sibling smoking and the risk of smoking uptake in childhood and adolescence: a systematic review and meta-analysis. Thorax 2010;2011:153379.

31 Lynch KL, Twesten JE, Stern A, et al. Level of alcohol consumption and successful smoking cessation. Nicotine Tob Res 2019;21:1058-64.

32 Cook JW, Fucito LM, Piasecki TM, et al. Relations of alcohol consumption with smoking cessation milestones and tobacco dependence. J Consult Clin Psychol 2012;80:1075-85.

33 Yamaya Y, Sugiya H, Watari T. Tobacco exposure increased airway limitation in dogs with chronic cough. Vet Rec 2014;174:18.1-18.

34 Bertone ER, Snyder LA, Moore AS. Environmental and lifestyle risk factors for oral squamous cell carcinoma in domestic cats. $J$ Vet Intern Med 2003;17:557-62.

35 Wilson S, Hill L. What is the paramedic's role in smoking cessation? J Paramed Prac 2019;11:100-5.

36 Vinnikov D, Lahdensuo A, Brimkulov N. Medical students of Kyrgyzstan: smoking prevalence and attitudes to smoking cessation counseling. Prevent Cont 2006;2:31-7. 